\title{
Factors Affecting the Use and Development of Solar Energy in Iran's Agricultural Sector
}

\author{
Mohsen Mohammadia* and Gholamreza Yavaria
}

a Faculty of Agriculture, Payam-e-Noor University, Tehran, Iran

\begin{abstract}
The paper seeks to identify factors led some farmers to use renewable energy in their poultry farms. The research was a practical study in terms of goal and a descriptive-correlation study in terms of methodology. The population of the study was composed of Semnan Province poultry farmers that used any type of renewable energy in their farms. Based on the farmer's viewpoints, the most important factors made farmers use renewable energy in their poultries were poultry farm revenue, bank loans with low interest rate, and technology and equipment availability. Also, according to stepwise regression, $78.4 \%$ of the variance of the dependent variable was accounted for by the variables of economic, technical, subsidies reform, and policies factors. Therefore, financial incentives such as bank loans with low interest, distribution of technical equipment requirements and supportive legislation can be effective on the development of renewable energy use among other farmers.
\end{abstract}

Keywords: Agriculture, Renewable Energy, Fossil, Fuel, Sustainability

Article History: Received Nov 16 ${ }^{\text {th }}$ 2016; Received in revised form January 12nd 2017; Accepted $3^{\text {rd }}$ February 2017; Available online

How to Cite This Article: Mohammadi, M and Yavari, G. (2017) Factors affecting the use and development of solar energy in Iran's agricultural sector. International Journal of Renewable Energy Development, 6(1),45-53.

http://dx.doi.org/10.14710/ijred.6.1.45-53

\section{Introduction}

Sustainability is one of the key concerns of modern society, and the development of sustainable agriculture in terms of food security, climate change, nature conservation, biodiversity, and long-term resilience is among the big challenges in the world (Neo \& Alrøe, 2015; Merfield et al. 2015). The idea of the sustainable agriculture has gained prominence since the publication of the Brundtland Report in 1987. Yet, the concept is very vague and ambiguous in its meaning, which renders its use and implementation extremely difficult (Velten et al. 2015).

Sustainable agriculture comprises management procedures that work with natural processes to conserve all resources, minimize waste and environmental impact, prevent problems, and promote agro ecosystem resilience, self-regulation, evolution and sustained production for the nourishment and fulfillment of all. Under the dual constraints of global fossil energy's increasing depletion and the ecological environment rapid deterioration, developing renewable energy has become a strategic choice for building a sustainable energy system and achieving a low-carbon economy in many countries, which is also an important path for implementing the concept of sustainable development (Zhao \& Guo, 2015). Future agricultural sustainability will be achieved from an equilibrated solution of many productive, environmental, and economic issues. Among these, improved energy efficiency and reduced greenhouse gas emissions are fundamental (Alluvione et al. 2011).

Energy supply is a crucial strategy in any country. As seen in the current century, even large and costly wars happened and many people were killed to keep the possession of its energy resources (Yergin, 2006; Fouquet, 2013). The importance lies in the fact that almost all human manufacturing and service activities are dependent on a form of energy. So, it is essential for the politicians to ensure long-run energy supply with less cost and risks (Keyhani et al. 2010).

Energy is divided into renewable and non-renewable types. Non-renewable energy resources include those that pollute environment, and their replenishment will take billions of years. Fossil energy falls into this category (Freris \& Infield, 2008).

* Corresponding author: as.mohsen.mohammadi@gmail.com 
The term "Renewable Energy" includes a wide variety of sources which produce energy in different forms, with different efficiencies, with different land footprints, and at different costs. Just as agricultural products vary depending on the local environment, the best renewable technology varies as a function of the geographical location. In a wide array of possible renewable technologies, the obvious ones are those based on wind, sun, and flowing water, which include photovoltaic (PV), wind, hydroelectric, and biomass. To these, we may add geothermal energy (Bardi et al. 2013).

Renewable resources are continually replenished without human cost and without any contamination of the environment (Gholinezhad, 2009). The use of natural and renewable resources has attracted interests given the growing demand for energy and the depletion of fossil energy resources, the need for creating and maintaining maintain a stable environment, and restrictions on the transfer of energy from power plants to consumers in far areas. Renewable energies can return to nature. They are also named as green and clean energy (Ding et al. 2014).

Worldwide renewable technology is rapidly increasing in importance and deployment (Fouquet, 2013). In addition of other manufacturing and service sectors, the agricultural sector should extend the use of these resources. Modern agriculture is heavily based on the energy supply obtained mainly from fossil fuels. In this sense, it can be defined as a technology that transforms fossil fuels into food (Bardi et al. 2013).

Energy, especially electrical energy, is one of the main inputs required per unit of poultry farming. Generally, the electricity is needed to supply the power for electric motors, lighting halls, premises and rooms, cooling, air conditioning, heating and feeding systems (Byrne et al. 2005).

According to 2011 census by the Statistics Centre of Iran, there are approximately 19,000 poultry farms out of which 17,000 units are active. 512 units are in Semnan province out of which 389 units are active. The capacity of poultry farming production is approximately 8.6 million tons per year (Statistical Centre of Iran, 2012). The volume of financial turnover is $\$ 2.5$ billion and 100,000 peoples are currently employed in the poultry farming industry. Farms fuel consumption totalled 1400 thousand cubic meters of gas in 2003, equivalent to 40 percent of agricultural consumption and per capita consumption of each hen was 2 litters (SabzPoushani et al. 2011).

According to the report of Statistical Centre of Iran, the total power cost of poultry farming in Iran amounted to 149 billion IRR in 2011 (Statistical center of Iran, 2011).

Iran's geography is such that some parts receive a high volume of solar energy, over $70 \%$ of which is recoverable. Also, some regions are on the winds path over several months (Satkin, 2013).
Iran is a vast country located between the latitudes of $25^{\circ} 3^{\prime}$ and $39^{\circ} 47^{\prime} \mathrm{N}$. and the longitudes of $44^{\circ} 5^{\prime}$ and $63^{\circ} 18^{\prime}$ E. Solar radiation in this area is at a high level. The amount of solar radiation in Iran (about 2000 $\mathrm{kWh} / \mathrm{m} 2 / \mathrm{y}$ ) is one of the greatest values in the world. For example, in Germany, the amount of solar radiation $(800-1000 \mathrm{Kwh} / \mathrm{m} 2 / \mathrm{y})$ is less than half average of that in Iran. With an area of approximately 1.648 million kilometres, the total amount of radiation is about 3.3 million $\mathrm{Tw} / \mathrm{h} / \mathrm{y}$, which is thirteen times as great as total energy consumption in Iran. The optimum potential of solar energy in many parts of the country has provided fertile ground for the use of solar equipment (Hashemi \& Koroni, 2012). Solar power is an important and widely used renewable energy type. Solar radiation and heat are converted into solar energy, which is used to generate electric power. This renewable energy source is abundant, especially in tropical countries. Besides being used in electric power generation, solar energy has been widely used to supply electric power to many personal portable devices. This renewable energy type is more flexible than the other renewable energy sources, and its initial setup requires a relatively small investment. However, energy storage is essential to supply energy demands in the absence of sunlight (Wee et al. 2012).

There are many alternative new and renewable energy sources which can be used instead of fossil and conventional fuels. The decision as to what types of energy source should be utilized must, in each case, be made on the basis of economic, social, environmental and safety considerations (Demirbas, 2005).

Studies show the possibility of using renewable energy in poultry farming and proved the benefits of renewable resources in agriculture (Okonkwo and Chukwuezie, 2012; SabzPoushani et al. 2011).

Solar energy can be used in different forms that each of these forms have require the necessary equipment. Solar radiations use as source of lightening directly and indirectly. In directly form we have built the number of windows in the hall. Therefore, the hall will be bright during the day with direct sunlight (Fig. 1).

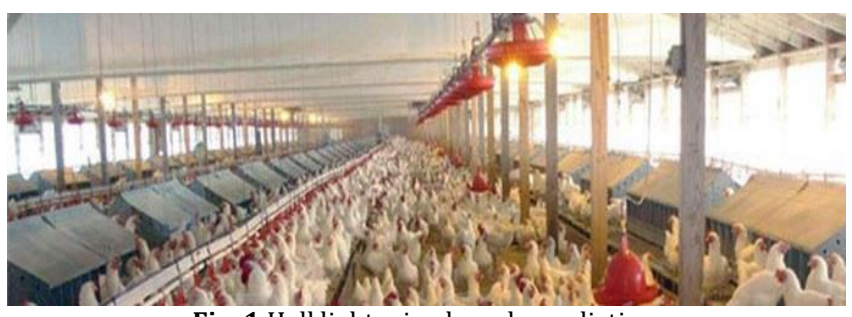

Fig. 1 Hall lightening by solar radiation

Also by converting solar energy into electric energy and storing it we can lighting hall, room and ambient. In this case, we can use of solar lamps (Fig. 2) or transfer the energy from a central storage system to lights. In the first method power of energy's output is low but instead requires less equipment and is less costly. In the second 
method, a large number of photocells are install in the environment. These cells convert solar energy into electrical energy and stored in battery resources. Obtained energy can be used for lighting by lamp, cooling halls by fan.

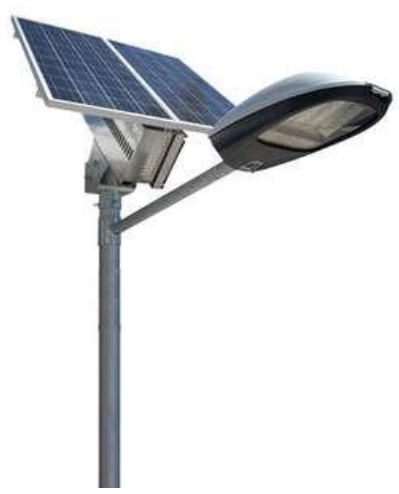

Figure 2. Solar lamp

The solar water heaters are also used for heating the water. The water heater converts solar energy into heat energy and thus water inside the tubes are heated. Hot water can be transported by piping into the house, and another place (Fig. 3).

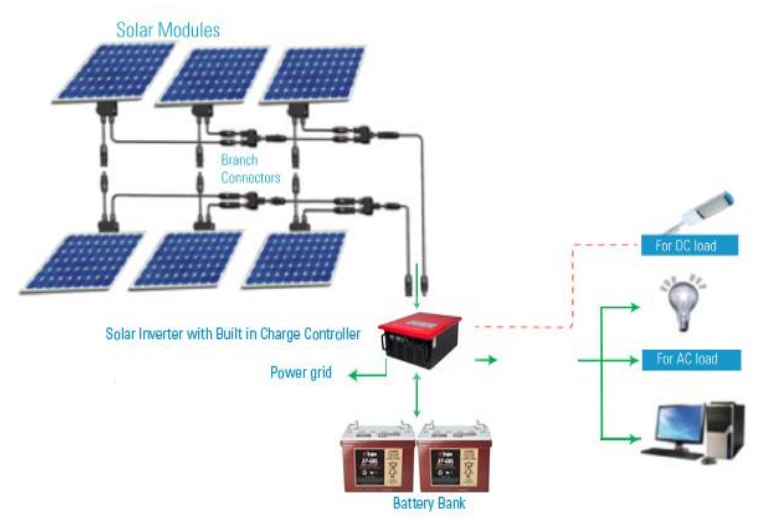

Figure 3. Solar panel diagram

Some farmers have been able to reduce costs and increase their income by using renewable resources. Also, they have helped the stability of the environment by reducing fossil fuels. Now in addition to the advantages of renewable energy and the disadvantages of fossil fuels and also Iran's renewable energy capacity, considering the fact that some farmers already use this type of energy in their farms, what factors have led some farmers to use this type of energy in their farms and how can the use of renewable energy among other farmers be developed?

So, this paper aims at studying the factors that led some farmers to renewable energy in their farms and provide the necessary solutions for developing the use of these resources among other farmers.

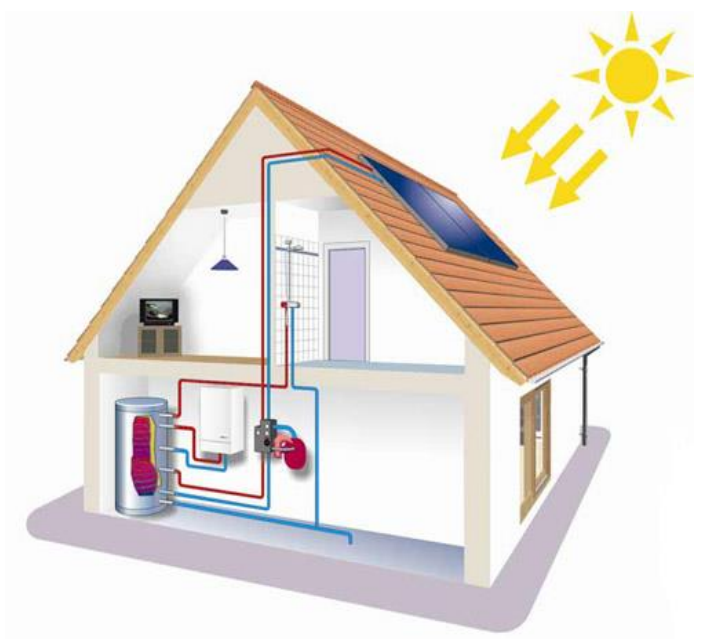

Figure 3 Solar water heater

\section{Review of Literature}

Yohanna and Umogbai (2010) discussed a study in Nigeria to investigate the feasibility of using solar energy in agriculture and poultry farming. In the poultry farming sector, solar energy can be used in several phases including incubation, hot chicks' artificial mothers during the first days to weeks, conditioning halls, pavilions and track lighting and water heating requirements of poultry farming, including those that may be required to use the sun to provide energy. These resources are already used in various sectors of Nigerian agriculture and could be developed with government support and training.

Stigka et al. (2014) argued that economic and institutional factors include economic conditions in the region, problems with (public or private) ownership, lack of financial incentives, high investment costs compared to installations relying on the combustion of conventional fuels, inefficiencies in the existing legal framework, and bureaucratic problems or complex licensing. Technical and planning factors include local geography, process problems for the selection of an appropriate application site, planning problems, issues with the previous use of the chosen location, and impacts related to the distance of residents from the power plants (such as visual intrusion and noise pollution). Finally, factors related to the perceptions of the public include the lack of information or knowledge on the new technologies, mistrust, lack of impartiality, and suspicion towards investors are the barriers of the renewable energy development.

Financing institutions should promote appropriate safeguards, supported by capacity building activities from international organizations, in order to unleash the full sustainable potential of renewable energy options (Athanas \& McCormick, 2013).

Bardi et al. (2013) discussed that the short-term financial resources are very important for the use of 
renewable energies in agriculture sector. Ferreira et al. (2012) argue that policy is essential if the academic community is to capitalize effectively on recent government investments in research and provide the necessary evidence basis for reconciling agricultural production and environmental conservation in Brazil.

Fami et al. (2010) in their study found that the majority of the respondents used renewable energy and materials directly in its traditional forms without enabling technologies, and that they lacked the access to renewable technologies to improve the efficiency of energy use. They preferred fossil energy for many activities due to its lower cost and ease of access. They argued that there were potentials and capacities for using renewable energies and materials in the farming systems of the Tafresh township. The government has to support and encourage the adoption of renewable technologies and abandon fossil fuels wherever possible.

While there are ambitious government targets to increase the share of renewable energy in many countries, it is increasingly recognized that social acceptance may be a constraining factor in achieving this target. This is particularly apparent in the case of wind energy, which has become a subject of contested debates in several countries largely due to its visual impact on landscapes (Wüstenhagen et al. 2007).

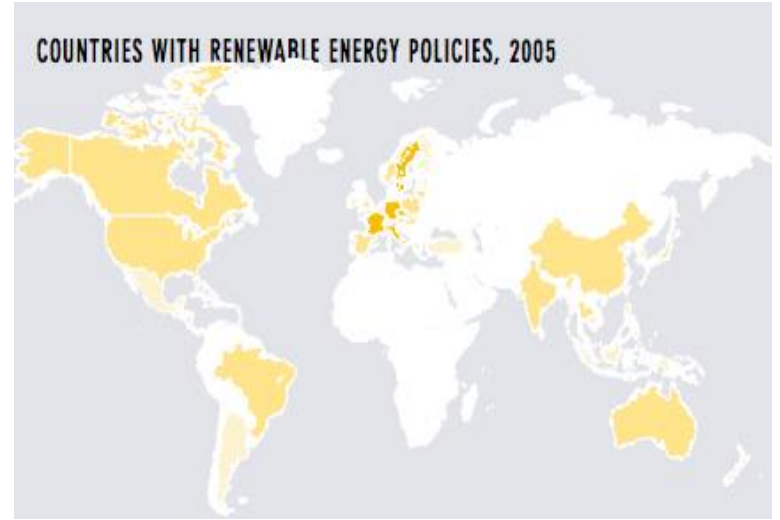

Figure 5 Amounts of renewable energy policies in 2005 (Shahan, 2013)

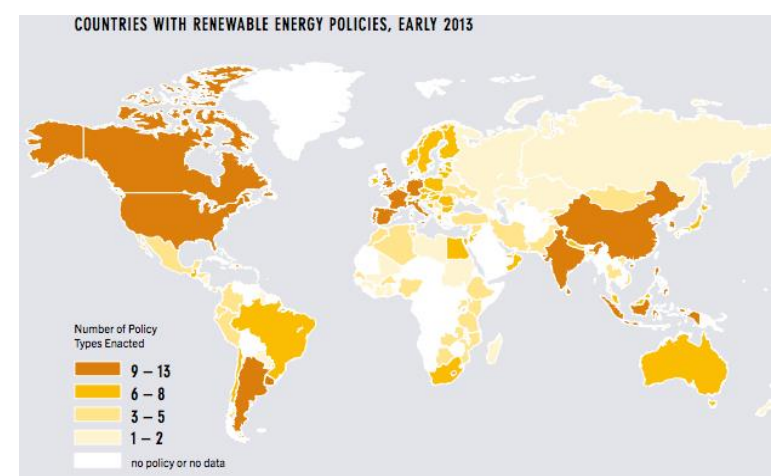

Figure 6 Amounts of renewable energy policies in 2013 (Shahan, 2013)
Ioakeimidis et al. (2013) propose a framework for energy audit and renewable energy utilization for a Mediterranean fish hatchery station. They argue that the project is economically viable and could be realized, provided that the necessary financial resources become available to the entrepreneurs. Farajallah Hosseini et al. (2012) proved the importance of extension and awareness presentations by the extension agents on the use of clean energy technology.

Martin and Rice (2012) believe that the factors impacting the development of renewable energy include finance (such as high project capital costs, insufficient financial incentives, project finance availability, power purchase agreements), infrastructure (such as insufficient network capacity and remote grid connections and access), technical (such as technology intermittency and storage and lack of skilled workforce), regulation (such as complex zoning and planning, multi-tiered government approvals and land access and use) economic (such as abundant fossil fuel resources and cheap coal fired power), information, education, and awareness.

One of the factors in the development of renewable energy is the policies. Existence of local and national laws of renewable energy prohibits legislation of using fossil resources, financial regulation and tax on greenhouse gas emissions and other policies. Accordingly, the government also enacted laws to try to develop it. The rate of the renewable energy policies growth are shown in Figures 5 and 6 (Shahan, 2013).

Supportive policies are necessary to foster development and deployment of different technologies of renewable energies (Hinrichs-Rahlwes, 2013). MuradSharifi et al (2009) studied the role of technical learning on the development of renewable energy sources and proved its effectiveness and also found that state interference in the pricing of energy had a negative role.

SabzPoushani et al (2011) presented a method based on the use of solar energy for heating poultry halls in cold climates (Hamadan) and moderate climates (Tehran). The results showed that for colder climate, the combined solar collector and floor heating system are capable to supply about 25 percent of annual heating needs and about 30 percent of Tehran's poultry farming halls. Capital return period was calculated for Tehran as about 6.4 years and for Hamadan as about 4.7 years. According to high life of expressed system, replacing traditional heating systems with combined systems showed high economic efficiency.

Eder et al (2015) identified three critical dimensions as crucial for renewable energy adoption: technical, economic, and social. First, there was an emphasis on the relative advantages of the new technology. Second, there were economic requirements regarding a viable financial system for adopters, especially in such a low-income market. Third, the social dimension was critical, particularly the 
importance of foreign firms collaborating with local actors.

Liu et al. (2013) discussed rural public acceptance of renewable energy deployment in their study. They found more willingness to pay for renewable electricity and found that it was increased with people's education and social situation, knowledge and beliefs about cost of renewables.

Ahlborg and Hammar (2014) argued that such factors as local and national laws, unreal tariff, tax, investment cost, and fossil fuel subsidies had effective roles in the adoption of renewable energy.

\section{Materials and Methods}

The present paper seeks to identify factors leading some farmers to use renewable energy in their poultry farms in Iran.

Study methods: This research is an applied study in terms of goal and a descriptive-correlation in terms of methodology which was carried out by survey.

Study area and population: With an area of 97,490 $\mathrm{km} 2$, Semnan Province composes $5.9 \%$ of the total area of the country. It is the sixth largest province of Iran. Its area is almost quadruple of Tehran Province. This province is located between latitudes of $34^{\circ} 17^{\prime}$ and $37^{\circ} 30^{\prime} \mathrm{N}$ and longitudes of $51^{\circ} 58^{\prime}$ and $57^{\circ} 58^{\prime} \mathrm{E}$. According to the Iranian Statistics Centre, 2011 census reports that there are approximately 19,000 poultry farms of which 17,000 farms were active. Of these, 512 units are in Semnan Province and 397 units are active (Statistical Centre of Iran, 2012). The population of this study was composed of poultry farmers of Semnan Province that were using renewable energy - especially solar energy - in their poultry in any form (hall heating, hall cooling, hall lighting, hall air conditioning, ambient lighting, hot water supply). There are eight townships and towns in Semnan Province. Among active farms, 20 poultries were found to use renewable energy in their farms as presented in Table 1.

Finally, the size of the population was 33 peoples. Due to the small number of poultry farms that used renewable energy, data were collected through the census. Frequency and distribution of using any type of renewable resources are expressed in Table 2.

Tabel 1

Frequency and distribution of population

\begin{tabular}{|c|c|c|c|}
\hline Township/Town & $\begin{array}{c}\text { Active } \\
\text { poultries }\end{array}$ & $\begin{array}{l}\text { Renewable } \\
\text { energy user }\end{array}$ & $\begin{array}{l}\text { Number of } \\
\text { informed }\end{array}$ \\
\hline Semnan & 53 & 3 & 6 \\
\hline Sahroud & 87 & 2 & 4 \\
\hline Garmsar & 50 & 4 & 6 \\
\hline Damghan & 49 & 1 & 1 \\
\hline Aradan & 48 & 3 & 5 \\
\hline Mahdishahr & 31 & 1 & 2 \\
\hline Sorkhe & 68 & 4 & 7 \\
\hline Meyamey & 11 & 2 & 2 \\
\hline Total & 397 & 20 & 33 \\
\hline
\end{tabular}

Source: survey data

Data collecting tools: Data collection tool was a questionnaire (with 11 main questions and 67 minor questions on a Likert scale). The questionnaire was designed after consultations with university professors and research assumptions and also according to the review of literature. Interviews with experts and university professors, documents and Internet search were also used for data collection. Validity of the questionnaire was measured by face validity method and its reliability was tested with Cronbach's alpha which ranged from 0.791 to 0.912 .

\subsection{Research variables}

In terms of research objectives, dependent variable was "the use of renewable energy in poultry farming".

Tabel 2

Type of renewable energy being used

\begin{tabular}{|c|c|c|c|c|c|c|c|c|}
\hline & Semnan & Sahroud & Garmsar & Damghan & Aradan & Mahdishahr & Sorkhe & Meyamey \\
\hline Hall heating & 1 & 0 & 1 & 0 & 1 & 0 & 2 & 0 \\
\hline Hall cooling & 1 & 0 & 1 & 0 & 0 & 0 & 1 & 0 \\
\hline Hall lighting & 2 & 2 & 2 & 0 & 2 & 0 & 3 & 0 \\
\hline Hall air conditioning & 0 & 0 & 1 & 0 & 0 & 0 & 1 & 0 \\
\hline Ambient lighting & 3 & 2 & 4 & 1 & 3 & 1 & 4 & 2 \\
\hline Solar water heating & 3 & 2 & 4 & 1 & 3 & 1 & 3 & 1 \\
\hline
\end{tabular}

Tabel 3

Cronbach's alpha coefficients of questionnaire

\begin{tabular}{clc}
\hline & Question & coefficients \\
\hline 1 & Education roles & 0.909 \\
2 & Farmer's views & 0.912 \\
3 & Energy supply & 0.910 \\
4 & Technical requirements & 0.863 \\
5 & Laws and regulations & 0.901 \\
6 & Economic factors & 0.874 \\
7 & Education and extension methods & 0.895 \\
8 & Social and cultural activities & 0.903 \\
9 & Subsidy reform law & 0.841 \\
10 & Barriers to use renewable energy in poultry farming & 0.796 \\
11 & Willingness and necessity of using renewable energy in poultry farming & 0.791 \\
\hline Source: survey data &
\end{tabular}

In order for the investigation of factors affecting the use of renewable resource by some farmers, independent variables were divided into six main fields using the technique of exploratory factor analysis as follows:

- Technical factors containing knowledge and technical skills, renewable resource potential, technology and equipment existence, survey studies and land providing,

- Political factors containing local laws, legislation to protect the environment, providing legal incentives, tax breaks and mandatory policies, 
- Economic factors containing poultry farm revenue, actual pricing of fossil energy, bank loans with low interest rates and investment by private sector,

- Education and extension factors containing extension methods and public education,

- Social factors containing public culture, public acceptance of new energy and distribution of saving culture, and

- Subsidies reform containing full implementation of the subsidies reform.

Before filling out questionnaires, the professional and supplementary educational materials were presented to farmers. Questionnaires were completed in a face-to-face meeting with participants and were analysed by IBM SPSS Ver. 20 Software Package. This study was carried out in 2015.

\subsection{Research hypotheses}

Six hypotheses were tested to study the relationships of technical, policy, economic, education and extension, social and subsidies reform factors with the use of renewable energy by farmers. Pearson and Spearman tests were used to test the hypotheses. As well, multiple regression was used to simultaneously measure the independent variables on the dependent variable.

\section{Results and Discussion}

The most frequent class of people's age was 41-50 years with the frequency of 17 (51.51\%), and the lowest frequency was under 30 years with the frequency of 0 $(0 \%)$. So, young peoples are lowly active in this job.

Tabel 4

\begin{tabular}{|c|c|c|c|}
\hline Frequency distribution Table of farmers \\
\hline Individual attributes & Class & Frequency & Percentage \\
Age & Under 30 & 0 & 0 \\
$\mathrm{n}=33$ & $31-40$ & 6 & 18.18 \\
$\mathrm{SD}=9.793$ & $41-50$ & 17 & 51.51 \\
Mean $=44$ & $51-60$ & 8 & 24.25 \\
& 60 and above & 2 & 6.06 \\
& Under & & \\
& diploma & 0 & 0 \\
Level of Education & Diploma & 6 & 18.18 \\
$\mathrm{n}=33$ & Associate & 5 & 15.14 \\
Mode $=$ license & degree & 13 & 39.40 \\
& B.Sc. & 9 & 27.28 \\
& M.Sc. and & & \\
\hline Types of poultry & above & & \\
farming & private & 1 & 2.20 \\
$\mathrm{n}=33$ & Non-private & 32 & 97.80 \\
Mode = Non-private & & & \\
\hline
\end{tabular}

Source: survey data

According to Table 4, most people's educational degree is B.Sc. with the frequency of 13 (39.40\%) and the least number had under-diploma degree with the frequency of $0(0 \%)$ indicating that farmer's educational level was acceptable. Based on the results, 32 peoples
$(97.80 \%)$ were members of non-private farms and 1 person $(2.20 \%)$ worked in private farms.

Based on the farmer's viewpoints, the most important factor leading farmers to use renewable energy in their poultries was "Poultry farm revenue" $(\mathrm{C} . \mathrm{V}=0.257)$. As mentioned, more than 97 percent of farmers work as non-private and cooperative farming. So, they can meet the costs of purchasing equipment for utilizing renewable resources. The second factor was "Bank loans with low interest rate " (C.V = 0.302). Initial funding for new technologies has always been a problem for farmers, which can be resolved by bank loans with low interest rates and long repayment duration. Third factor was "Technology and equipment availability" (C.V = 0.336). Providing the required equipment in suitable area allows farmers to ensure supplying it. Farmers must be aware of technology applications and touch it.

Tabel 5

Ranking of factors leading farmers to use renewable energy

\begin{tabular}{|c|c|c|c|c|}
\hline Item & Mean & $\begin{array}{c}\text { Std. } \\
\text { Deviation }\end{array}$ & C.V & Rank \\
\hline Poultry farm revenue & 3.97 & 1.02 & 0.257 & 1 \\
\hline $\begin{array}{l}\text { Bank loans with low interest } \\
\text { rate }\end{array}$ & 4.11 & 1.24 & 0.302 & 2 \\
\hline $\begin{array}{l}\text { Technology and equipment } \\
\text { availability }\end{array}$ & 3.45 & 1.16 & 0.336 & 3 \\
\hline Knowledge and technical skills & 3.47 & 1.18 & 0.341 & 4 \\
\hline Investment by private sector & 3.08 & 1.08 & 0.351 & 5 \\
\hline Renewable resource potential & 3.65 & 1.33 & 0.364 & 6 \\
\hline $\begin{array}{l}\text { Full implementation of the } \\
\text { subsidies reform }\end{array}$ & 3.39 & 1.33 & 0.392 & 7 \\
\hline Distribution of saving culture & 3.90 & 1.59 & 0.408 & 8 \\
\hline Public education & 2.78 & 1.23 & 0.442 & 9 \\
\hline Provide legal incentives & 4.01 & 1.86 & 0.464 & 10 \\
\hline Survey studies & 3.51 & 1.63 & 0.464 & 11 \\
\hline Actual pricing of fossil energy & 3.27 & 1.53 & 0.468 & 12 \\
\hline Local laws & 3.75 & 1.77 & 0.472 & 13 \\
\hline Land supply & 2.38 & 1.13 & 0.475 & 14 \\
\hline Public culture & 3.92 & 1.88 & 0.480 & 15 \\
\hline Mandatory policies & 3.54 & 1.77 & 0.500 & 16 \\
\hline $\begin{array}{l}\text { Public acceptance of new } \\
\text { energy }\end{array}$ & 3.10 & 1.62 & 0.523 & 17 \\
\hline Extension methods & 3.09 & 1.67 & 0.540 & 18 \\
\hline Tax breaks & 3.15 & 1.74 & 0.552 & 19 \\
\hline $\begin{array}{l}\text { Legislation to protect the } \\
\text { environment }\end{array}$ & 2.66 & 1.73 & 0.650 & 20 \\
\hline
\end{tabular}

4.1 Hypothesis A: There are relationships between technical factors and the use of renewable energy by farmers.

Pearson's correlation coefficient was used to examine the relationship between technical factors and the use of renewable energy by farmers. According to the results, the significance level is 0.003 that is smaller than $\alpha=0.05$ and $r=0.582$. So, it can be accepted that there is a direct relationship between them. Stigka et al. (2014), Martin and Rice (2012), MuradSharifi et al. 
(2009), Eder et al. (2015) and Fami et al. (2010) have proved this hypothesis in their study.

\subsection{Hypothesis B: There is a relationship between policy and the use of renewable energy by farmers.}

To test the relationship between policy and using renewable energy in poultry farming, the Pearson's correlation coefficient was used. The significance level is 0.007 and $r=0.638$. Therefore, it can be concluded that there is a relationship between governmental policy and the use of renewable energy in poultry farming. Stigka et al. (2014), Ferreira et al. (2012), Martin and Rice (2012), Hinrichs-Rahlwes (2013), Shahan (2013) and Ahlborg and Hammar (2014) have proved this hypothesis in their study.

4.3 Hypothesis C: There is a relationship between the economic factors and the use of renewable energy in poultry farming.

Pearson's correlation coefficient was used to test relationship between the economic factors and the use of renewable energy in poultry farming. The significance level was found to be sig. $=0.000$ that is smaller than $\alpha=0.01$, and $r=0.741$. Thus, it can be said that the economic factors are related to the use of renewable energy in poultry farming with 99\% correlation. Ahlborg and Hammar (2014), Stigka et al. (2014), Ioakeimidis et al. (2013) Martin and Rice (2012), SabzPoushani et al. (2011), Bardi et al. (2013) and Eder et al. (2015) have proved this hypothesis in their study.

4.4 Hypothesis D: There is a relationship between the education and extension factors and the use of renewable energy in poultry farming.

Pearson's correlation coefficient was used to test the relationship between the education and extension factors and the use of renewable energy in poultry farming, according to which we have significance = 0.012 and $r=0.495$. So, it can be said there is a relationship between the education and extension factors and the use of renewable energy in poultry farming. Yohanna and Umogbai (2010), Stigka et al. (2014), Farajallah Hosseini et al. (2012), Liu et al. (2013) and Martin and Rice (2012) have proved this hypothesis in their study.

4.5 Hypothesis E: There is a relationship between the social factors and the use of renewable energy in poultry farming.

The correlation test showed that the significance $=$ 0.005 which is smaller than $\alpha=0.01$ and $r=0.746$. Hence, it can be said there the use of renewable energy in poultry farming is related to the social factors with $99 \%$ correlation. Wüstenhagen et al. (2007), Liu et al.
(2013) and Eder et al. (2015) have proved this hypothesis in their study.

4.6 Hypothesis F: There is a relationship between the subsidies reform and using renewable energy in poultry farming.

To test the relationship between subsidies reform and using renewable energy in poultry farming, the Pearson's correlation coefficient was used. The significance level was 0.017 and $r=0.623$. Therefore, we can conclude that there is a relationship between subsidies reform and using renewable energy in poultry farming. Ahlborg and Hammar (2014) reported similar results.

Tabel 6

Result of correlation test

\begin{tabular}{|c|c|c|c|}
\hline & Independent Var. & $\mathbf{r}$ & Sig. \\
\hline \multirow{5}{*}{$\begin{array}{c}\text { Technical } \\
\text { factors } \\
\mathrm{r}=0.582 \\
\text { sig }=0.003\end{array}$} & Knowledge and technical skills & $0.614 * *$ & 0.000 \\
\hline & Renewable resource potential & $0.611 * *$ & 0.000 \\
\hline & $\begin{array}{l}\text { Technology and equipment } \\
\text { existence }\end{array}$ & 0.132 & 0.216 \\
\hline & Survey studies & $0.600 *$ & 0.031 \\
\hline & Land providing & $0.651 * *$ & 0.000 \\
\hline \multirow{5}{*}{$\begin{array}{c}\text { Policy } \\
\mathrm{r}=0.638 \\
\operatorname{sig}=0.007\end{array}$} & Local laws & 0.339 & 0.072 \\
\hline & $\begin{array}{l}\text { Legislation to protect the } \\
\text { environment }\end{array}$ & $0.401 *$ & 0.026 \\
\hline & Provision of legal incentives & $0.586 * *$ & 0.000 \\
\hline & Tax breaks & $0.598 * *$ & 0.005 \\
\hline & Mandatory policies & 0.487 & 0.093 \\
\hline \multirow{4}{*}{$\begin{array}{c}\text { Economic } \\
\mathrm{r}=0.741 \\
\mathrm{sig}=0.000\end{array}$} & Poultry farm revenue & $0.615 * *$ & 0.003 \\
\hline & Actual pricing of fossil energy & $0.557 * *$ & 0.000 \\
\hline & Bank loans with low interest rate & $0.336 *$ & 0.038 \\
\hline & Investment by private sector & $0.511 * *$ & 0.000 \\
\hline \multirow{2}{*}{$\begin{array}{c}\text { Education } \\
\mathrm{r}=0.495 \\
\text { sig }=0.012\end{array}$} & Extension methods & $0.787 * *$ & 0.004 \\
\hline & Public education & $0.615 * *$ & 0.000 \\
\hline \multirow{3}{*}{$\begin{array}{c}\text { Social } \\
\text { factors } \\
\mathrm{r}=0.746 \\
\mathrm{sig}=0.005\end{array}$} & Public culture & $0.417 *$ & 0.022 \\
\hline & Public acceptance of new energy & $0.309 * *$ & 0.000 \\
\hline & Distribution of saving culture & $0.523 * *$ & 0.000 \\
\hline $\begin{array}{c}\text { Subsidies } \\
\text { reform } \\
r=0.623 \\
\text { sig }=0.017\end{array}$ & $\begin{array}{l}\text { Full implementation of the } \\
\text { subsidies reform }\end{array}$ & $0.017 *$ & 0.017 \\
\hline
\end{tabular}

Source: survey data

\subsection{Multiple regression}

In this study, stepwise regression was used to simultaneously measure the effect of independent variables on the dependent variable (the use of renewable energy in poultry farming of Iran). Multiple regression is a technique that assesses multiple independent variables that can impact on the dependent variable simultaneously. In this way, each of 
the variables is individually entered to the model and the process continues until it reaches the $95 \%$ significance level variable (Mansoorfar, 2007).

According to Table 6, there are a relationship between all independent variables and using renewable energy in poultry farming. So, we entered all 6 independent variables in the multiple regression. Based on the results, the first variable that was entered into the regression equation was "Economic". So, it can be said that these variables have the greatest impact on the dependent variable, more than any other variable entered into the equation. Correlation coefficient equals $\mathrm{R}=0.693, \mathrm{R} 2$ (adj) $=0.517$ and $\beta=1.255$. According to the coefficient of determination, it can be concluded that the "Economic" could explain 52\% of the variance of the dependent variable.

The second variable that was included in the regression was "Technical". The correlation coefficient for this variable was equal to $\mathrm{R}=0.742$, $\mathrm{R} 2$ (adj) $=0.653$ and $\beta=0.218$. This variable could alone account for $14 \%$ of the variance of the dependent variable.

Then, according to the results, "Subsidies reform" was entered in the regression equation at the third step. The correlation coefficient for this variable was found to be $\mathrm{R}=0.763$ and $\mathrm{R} 2$ (adj) $=0.691$ and $\beta=0.256$. Therefore, this variable could alone explain $4 \%$ of the variance of the dependent variable.

Finally, "Policies" was entered in the regression equation at the last step. The correlation coefficient was found to be $\mathrm{R}=0.802$ and $\mathrm{R} 2(\mathrm{adj})=0.784$ and $\beta=0.288$. Therefore, this variable could alone explain $2 \%$ of the variance the dependent variable.

Tabel 7

Stepwise regression analysis results

\begin{tabular}{llcccccc}
\hline & $\begin{array}{c}\text { Independent } \\
\text { Var. }\end{array}$ & $\begin{array}{c}\mathbf{R}^{\mathbf{2}} \\
(\mathbf{a d j})\end{array}$ & $\mathbf{( R )}$ & $\mathbf{T}$ & $\boldsymbol{\beta}$ & $\mathbf{B}$ & Sig. \\
\hline & Constant & - & - & 6.583 & - & 17.295 & 0.000 \\
1 & Economic & 0.517 & 0.693 & 5.765 & 1.255 & 1.723 & 0.008 \\
2 & Technical & 0.653 & 0.742 & 2.435 & 0.218 & 0.775 & 0.011 \\
3 & Subsidies & 0.691 & 0.763 & 3.568 & 0.256 & 0.413 & 0.005 \\
& reform & & & & & & \\
4 & Policies & 0.784 & 0.802 & 3.136 & 0.288 & 0.762 & 0.000 \\
\hline Source: survey data & & & & & &
\end{tabular}

According to $\mathrm{R}^{2}$ (adj) of row 4 in Table 7 , it can be said that $78.4 \%$ of the variance of the dependent variable was explained by the "Economic", "Technical", "Subsidies reform" and "Policies" variables. Also, the regression equation was obtained as bellow:

\section{$\mathrm{Y}=17.295+1.723$ (Economic) +0.775 (Technical) +0.413} (Subsidies reform) + 0.762 (Policies)

Based on the regression line equation, it can be concluded that in normal conditions there are about $17.295 \%$ of unknown margin factors that can expedite and facilitate the admission process of the use of renewable energy in poultry farming. The first important effective factor on the use of renewable energy is economic factors $(B=1.723)$. Technical factors are the second $(B=0.775)$, policies factors are the third $(\mathrm{B}=0.762)$ and subsidies reform factors are the forth effective factors. Finally, variables such as "Education and extension" and "Social factors" have a less than 95\% of significant level and are omitted from calculations.

\section{Conclusion}

This paper analyses the factors leading farmers to use renewable energy in their poultry farms and tries to find approaches for developing the use of these resources among other farmers.

This study finds that there is a significant relationship between all independent variables including technical, policy, economic, education and extension, subsidies reform, and social factors and the use of renewable resource by farmers. Base on the farmer's viewpoints, "Poultry farm revenue", "Bank loans with low interest rate " and "Technology and equipment availability" are important factors that resulted in the use of renewable energy in any type in poultry farms. Also, according to stepwise regression economic, technical, subsidies reform and policy known as effective factors on using renewable resource by farmers.

This result shows the importance of factors related on economic impellent and conditions, supportive policies, technical knowledge and equipment and subsidies spent. The farmers must be able to provide the initial cost of buying the equipment, to have access to the required technologies and equipment and technical knowledge and to be supported by national and local laws. Designing a good support system can help growth, cost reduction and progressive competitiveness of new technologies for a secure energy future. Broad political consensus about the necessary changes in renewable energies and energy efficiency and a reliable framework for investors can foster the growth and cost decreases, and at the same time, new small and medium market entrants will be encouraged. Also in order to increase farmers' willingness to use renewable resources - as one of the ways to protect the environment and sustainability in agriculture - extension agents can encourage other farmers to visit the farms in which these resources are used. This will allow farmers to become familiar with the benefits and to learn how to use this technology.

The overall conclusion is that financial incentives such as bank loans with low interest, distribution of technical equipment requirements and supportive legislation can be effective in the development of renewable energy among other farmers.

\section{References}

Ahlborg, H., \& Hammar, L. (2014) Drivers and barriers to rural electrification in Tanzania and Mozambique-Grid-extension, off- 
grid, and renewable energy technologies. Renewable Energy, 61, 117-24. doi: 10.1016/j.erss.2014.12.014

Alluvione, F., Moretti, B., Sacco, D., \& Grignani, C. (2011) EUE (energy use efficiency) of cropping systems for a sustainable agriculture. Energy, 36(7), 4468-4481. doi: 10.1016/j.energy.2011.03.075

Athanas, A. K., \& McCormick, N. (2013) Clean energy that safeguards ecosystems and livelihoods: Integrated assessments to unleash full sustainable potential for renewable energy. Renewable Energy, 49, 25-28. doi: 10.1016/j.renene.2012.01.073

Bardi, U., El Asmar, T., \& Lavacchi, A. (2013) Turning electricity into food: the role of renewable energy in the future of agriculture. Journal of Cleaner Production, 53, 224-231. doi: 10.1016/j.jclepro.2013.04.014

Byrne, J., Glover, L., Hegedus, S., \& VanWicklen, G. (2005) The potential for solar electric applications for delaware's poultry farms. Delaware: University of Delaware.

Demirbas, A. (2005) Potential applications of renewable energy sources, biomass combustion problems in boiler power systems and combustion related environmental issues. Progress in energy and combustion science, 31(2), 171-192. doi: 10.1016/j.pecs.2005.02.002

Ding, W., Wang, L., Chen, B., Xu, L., \& Li, H. (2014) Impacts of renewable energy on gender in rural communities of north-west China. Renewable Energy, 69, 180-189. doi: 10.1016/j.renene.2014.03.027

Eder, J. M., Mutsaerts, C. F., \& Sriwannawit, P. (2015) Mini-grids and renewable energy in rural Africa: How diffusion theory explains adoption of electricity in Uganda. Energy Research \& Social Science, 5, 45-54. doi: 10.1016/j.erss.2014.12.014

Fami, H.S., Ghasemi, J., Malekipoor, R., Rashidi, P., Nazari, S., \& Mirzaee, A. (2010) Renewable Energy Use in Smallholder Farming Systems: A Case Study in Tafresh Township of Iran. Sustainability, 2(3), 702-716. doi:10.3390/su2030702

Farajallah Hosseini, S.J., Soltani, Z., \& Ghiyasvand Ghiyasi, F. (2012) The role of solar energy in maintaining and restoring rangelands in dry areas. Journal of environmental studies, 6, 13-22.

Ferreira, J., Pardini, R., Metzger, J. P., Fonseca, C. R., Pompeu, P. S., Sparovek, G., \& Louzada, J. (2012) Towards environmentally sustainable agriculture in Brazil: challenges and opportunities for applied ecological research. Journal of Applied Ecology, 49(3), 535-541. doi:10.1111/j.1365-2664.2012.02145.x

Fouquet, D. (2013) Policy instruments for renewable energy-From a European perspective. Renewable Energy, 49, 15-18. doi: 10.1016/j.renene.2012.01.075

Freris, L., \& Infield, D. (2008) Renewable Energy in Power Systems. UK: Wiley.

Gholinezhad, A. (2009) Types of renewable energy. National Conference of fuel, energy and the environment. Tehran: Merc.

Hashemi, M., \& Koroni, M. (2012) Solar, Clean Energy (inquiry on sustainable development issues in Iran). Tehran: Kiyan Green Computing.

Hinrichs-Rahlwes, R. (2013) Renewable energy: Paving the way towards sustainable energy security: Lessons learnt from Germany. Renewable Energy, 49, 10-14. doi: 10.1016/j.renene.2012.01.076

Ioakeimidis, C., Polatidis, H., \& Haralambopoulos, D. (2013) Use of renewable energy in aquaculture: an energy audit case-study analysis. Global NEST. International Journal, 15(3), 282-294.

Keyhani, A., Marwali, M.N., \& Dai, M. (2010) Integration of Green and Renewable Energy in Electric Power Systems. New Jersey and Canada: Wiley.

Liu, W., Wang, C., \& Mol, A. P. (2013) Rural public acceptance of renewable energy deployment: The case of Shandong in China. Applied energy, 102, 1187-1196. doi: 10.1016/j.apenergy.2012.06.057

Mansoorfar, K. (2007) Advanced statistical methods with computer programs. Tehran: Tehran University Press.

Martin, N. J., \& Rice, J. L. (2012) Developing renewable energy supply in Queensland, Australia: A study of the barriers, targets, policies and actions. Renewable Energy, 44, 119-127. doi: 10.1016/j.renene.2012.01.006

Merfield, C., Moller, H., Manhire, J., Rosin, C., Norton, S., Carey, P., ... \& Le Quellec, I. (2015) Are Organic Standards Sufficient to Ensure
Sustainable Agriculture? Lessons from New Zealand's ARGOS and Sustainability Dashboard Projects. Sustainable Agriculture Research, 4(3), 158. doi: 10.5539/sar. v4n3p158

MuradSharifi, A., Aghaee, K., Sadeghi Shahdani, M., Dalali Isfahani, R., \& Shavalpour Arani, S. (2009) Effects of technological learning on the development of renewable energies in the electricity sector of disturbances in energy prices. Quarterly newsletter of Energy Economics, 21, 137-160.

Noe, E., \& Alrøe, H. F. (2015) Sustainable agriculture issues explained by differentiation and structural coupling using social systems analysis. Agronomy for Sustainable Development, 35(1), 133-144. doi: 10.1007/s13593-014-0243-4

Okonkwo, W.I., \& Chukwuezie, O.C. (2012) Characterization of a Photovoltaic Powered Poultry Egg Incubator. International Proceedings of Chemical, Biological \& Environmental, 47, 1-6.

SabzPoushani, M., Monemzadeh, M., \& Khorasanizadeh, H. (2011) Modeling and simulation solar collectors and floor heating hybrid systems for heating poultry halls. Energy efficiency Conference. Tehran: Institute of Technology Conference.

Satkin, M. (February 21, 2013) Iran is rich in renewable energy sources than oil. Accessed 25 August 2015 from http://www.yjc.ir/fa/print/4281732.

Shahan, Z. (2013) 18 Fun Renewable Energy Charts from NREL Director Dan Arvizu and Ren21's Renewables 2013 Global Status Report. Accessed 18 Oct, 2014 from: http://cleantechnica.com/2013/11/07/renewable-energycharts-renewable-energy-facts/.

Statistical center of Iran. (2012) Review survey results of Broiler poultry farms in 2011. Tehran: Strategic Planning and Supervision.

Statistical center of Iran. (2011) General Population and Housing Census 2011. Tehran: Statistical Center of Iran.

Stigka, E. K., Paravantis, J. A., \& Mihalakakou, G. K. (2014) Social acceptance of renewable energy sources: A review of contingent valuation applications. Renewable and Sustainable Energy Reviews, 32, 100-106. doi: 10.1016/j.rser.2013.12.026

Velten, S., Leventon, J., Jager, N., \& Newig, J. (2015) What Is Sustainable Agriculture? A Systematic Review. Sustainability, 7(6), 78337865. doi:10.3390/su7067833

Wee, H. M., Yang, W. H., Chou, C. W., \& Padilan, M. V. (2012) Renewable energy supply chains, performance, application barriers, and strategies for further development. Renewable and Sustainable Energy Reviews, 16(8), 5451-5465. doi: http://dx.doi.org/10.1016/j.rser.2012.06.006

Wüstenhagen, R., Wolsink, M., \& Bürer, M. J. (2007) Social acceptance of renewable energy innovation: An introduction to the concept. Energy policy, 35(5), 2683-2691. doi: 10.1016/j.enpol.2006.12.001

Yergin, D. (2006) Ensuring Energy Security. foreign affairs, 85(2), 6982.

Yohanna, J.K., \& Umogbai, V.I. (2010) solar energy potentials and utilization in nigeria agriculture. Journal of Environmental Issues and Agriculture in Developing Countries, 2(2,3), 10-21.

Zhao, H., \& Guo, S. (2015) External benefit evaluation of renewable energy power in China for sustainability. Sustainability, 7(5), 4783-4805. doi:10.3390/su7054783 